\title{
Stability Analysis of Two-line Rice Hybrids (Oryza sativa) in Diverse Environments Utilizing AMMI Model
}

\author{
Somanagoudra, Chandrashekhar* and S. Manonmani \\ Tamil Nadu Agriculture University, Coimbatore, India \\ *Corresponding author
}

\begin{tabular}{|l|}
\hline Ke y w o r d s \\
Stability Analysis, \\
Two-line Rice \\
Hybrids, \\
Oryza sativa \\
\hline Article Info \\
\hline $\begin{array}{l}\text { Accepted: } \\
\text { 18 May 2020 } \\
\text { Available Online: } \\
\text { 10 June 2020 }\end{array}$ \\
\hline \hline
\end{tabular}

\section{A B S T R A C T}

Genotype-environment interaction and stability analysis has been important for plant breeders and plays a vital role in identifying genotypes that are stable or unstable in each environment. Varieties that show low G x E interaction and high yield are desirable for crop breeders. The study was conducted in 2018 at six locations in India to (i) determine the presence of $\mathrm{G} \times \mathrm{E}$ of 171 single cross maize genotypes and (ii) To use the GGE biplot methodology to determine grain yield performance and stability of the genotypes evaluated across six environments. The effects of genotype and environment were significant $(\mathrm{P}<0.01)$ for grain yield. Pooled ANOVA analysis of 171 genotypes in six environments (E1-E6) showed highly significant differences for environments, significance of variance due to $G$ $\mathrm{x} \mathrm{E}$ in pooled analysis also indicated the presence of significant genotype $\mathrm{x}$ environment interaction. Genotypes G4, G74, G72, G6, G5 and G107 were high yielders with high interaction with environment. Genotypes G73, G159, G97 have highest positive IPCV values and G91, G32, G75 and G132 have highest negative IPCV values indicating that these are highly unstable genotypes. The two-line system has been widely applied for rice breeding since it has many advantages such as, two-line system has more extensive germplasm resources that is beneficial to the development of heterosis, better hybrid seed production yields, absence of negative effects associated with sterility-inducing cytoplasm especially on grain quality.

\section{Introduction}

Rice (Oryza sativa L.) is one of the most important staple foods worldwide, providing almost one-quarter of the global dietary energy supply for humans. The demand for food continues to rise as the population rapidly grows; necessitating the significant increase in production rice and arable land is limited together with environmental degradation. Rice is one of the most important food crops for half of the world's population. Worldwide, around 3.5 billion people depend upon rice for more than $20 \%$ of their calories requirement (Khush, 2013). India stands first in rice area with 44 million hectares and 
second in production with 105 million tonnes after China (IRRI, 2016). Rice production has increased tremendously from 34.5 million tonnes in 1960-61 to 112.91 million tonnes 2017-18 by developing high yielding semidwarf varieties, through crop management, adoption of hybrid varieties and plant protection practices.

The concept of two-line breeding emerged as an alternative to the three-line approach in China (Yuan, 1997). The main advantages of two-line heterosis breeding include the ability to use a wide range of genotypes as male parents, absence of negative effects associated with sterility-inducing cytoplasm and no need for maintainer lines. Male sterility in temperature sensitive genic male sterile (TGMS) lines is heritable. International Rice Research Institute has shown that two-line hybrids derived from TGMS lines had higher frequency of heterotic combinations than three-line hybrids derived from CMS lines (Lopez and Virmani, 2000).

Genotype-environment interaction and stability analysis has been important for plant breeders and plays a vital role in identifying genotypes that are stable or unstable in each environment. Varieties that show low $\mathrm{G} \times \mathrm{E}$ interaction and high yield are desirable for crop breeders and farmers, because it indicates that the environments have less effect on the performance of genotypes and their yield is largely due to the genetic composition (Linnemann 1995).

Among multivariate methods, the additive main effect and multiplicative interaction analysis (AMMI) has been extensively applied in the statistical analysis of multienvironment cultivar trials. A strong $\mathrm{G} \times \mathrm{E}$ interaction slows down selection and identification of genotypes and makes recommendations difficult. To analyze $\mathrm{G} \times \mathrm{E}$ interaction and phenotypic stability, several methods have been proposed, specifically univariate and multivariate stability statistics methods. A combined analysis of variance can quantify the interactions and describe the main effects (Genotype and Environment) reported by (Lin et al., 1986). The effectiveness of AMMI procedure has been clearly demonstrated by various authors and more specifically by Zobel et al. (1988) in soybean, Crossa et al. (1990) in maize and Mahalingam et al. (2018) in greengram using multilocation trial data. Ponnuswamy et al., 2017 reported in a study that AMMI and GGE biplots analyses were successful in assessing genotype by environment interaction in hybrid rice trials and aided in the identification of stable and adaptable rice hybrids with higher mean and stable yields. Jain et al., (2018) reported that estimates of genotype $\mathrm{x}$ environment interaction and additive main effect were significant for all the traits viz., grain yield, tiller/plant, plant height and panicle weight. Shams Shaila Islam et al., 2020 reported that highly significant differences were shown from the combined analysis for environments with grain yields, revealing that environments were different and indicated change ability between the genotypes and their interactions.

\section{Materials and Methods}

161 rice hybrids developed using 161 varieties crossed with one a TGMS line, PLIR75589TGMS at Hyderabad during November 2017 to May, 2018 seed production season. 161 hybrids along with 8 hybrid checks Viz., 25P35, 27P22, 27P31, 28P67, 27P37, PHB71, Arize 6444 Gold, US312 and 2 varietal checks Viz., MTU1010 and NDR-359 were evaluated at six locations viz., Patna (E1), Purnea (E2) in Bihar, Lucknow(E3), Gosaiganj (E4), Barabanki (E5) and Prayagraj (E6) in Uttar Pradesh during 2018 rainy season of 2018 from, June to October period. The evaluation sites are in 
the north central part of India (Figure1). A standard hybrid rice cultivation of practice as recommended by IIRR was adopted at each site during crop growth period. Evaluations were done under irrigated conditions. The genotypes were planted in a randomized complete block design with two replications. Each plot consisted 2-rows of 3.5-meter-long with 0.5 meter allay, with $20 \mathrm{~cm}$ space between rows and $15 \mathrm{~cm}$ between plants, accommodating 40 plants per entry per replication. Seedlings were raised in 5 meter by 1 meter raised nursery beds and transplanted into main field after puddling with 21-25 days old seedlings. Yield was calculated as $\mathrm{kg} / \mathrm{ha}$ after extrapolating yield per 40 plants to 330000 plants/ha $(15 \times 20 \mathrm{~cm}$ spacing) at standard $14 \%$ moisture for standardisation across entries as follows

Yield $(\mathrm{T} / \mathrm{ha})=\{($ Yield $/ 40$ plants $) * 330000 *$ (100-Moisture)/86\}/1000000

Analysis of variance was computed for the individual environment as well as for across environments. The significance of all effects was tested against the mean square of error.

The AMMI method was applied with additive effects to 171 genotypes in six environments, and multiplicative was used for $\mathrm{G} \times \mathrm{E}$ interaction. According to Sabaghnia et al. (2008), the AMMI method at first adjusts additive effects for host genotypes and environments through the normal additive analysis of variance (ANOVA) technique and fits multiplicative effects for $\mathrm{G} \times \mathrm{E}$ by $\mathrm{PCA}$. It affords a symbolic view of the transformed $\mathrm{G} \times \mathrm{E}$ interaction for any interpretation (Kempton, 1984). The statistical analysis computed using R programme.

\section{Results and Discussion}

Understanding of $\mathrm{G} \times \mathrm{E}$ interaction in plant species is of importance because it has implications for economic yield. In view of influence of environmental factors on crop growth, it is necessary to explore variation among genotypes (Anandan, 2011). From Table1, The ANOVA showed that mean squares due to genotypes were highly significant for grain yield in all (E1 to E6) environments, indicating differential performances of genotypes across environments, whereas ANOVA for replications showed no significant differences indicating the within non-significant location variation. Combined ANOVA analysis (Table 2) of 171 genotypes in six environments (Patna, Purnia, Lucknow, Gosaiganj, Barabanki, Prayagraj) showed highly significant differences for environments, significance of variance due to $G \times E$, indicated the presence of significant genotype $x$ environment interaction. The significance of genotypes mean squares indicated that genotypes differed among themselves and there existed a considerable variability irrespective of the effect of environments on the characters under study. The mean squares due to $\mathrm{G} \times \mathrm{E}$ interaction when tested against pooled error were significant for grain yield, hence the data was subjected to AMMI analysis.

In this study, the analysis of variance showed significance for PCA1 PCA2, PCA3,PCA4 and PCA5 (Table3). Among these, PCA 1, PCA2 and PCA3 together recorded 70.9 percent of total sum of squares. Hence, IPCA1, IPCA2, IPCA3may be used for explaining the $\mathrm{G} x \mathrm{E}$ interaction within study.

Table 5 shows IPCA1 and IPCA2 scores that characterize the interaction of a genotype across environments as well as relationships between genotypes and environments. According to Yan and Hunt (2001) and Mohammadi et al. (2007), a genotype with a positive IPCA score in several environments must neutralize negative interactions in other 
environments. Hence, these scores exhibit an unequal genotype reaction to the environment. Nevertheless, both positive and negative signs, as well as genotypes and environments using large IPCA scores, have strong large interactions and are stable. For grain yield the genotypes G72 (9.954 T/Ha),G74 (9.798 T/Ha),G58 $\quad(9.672$ T/Ha),G107 (9.621 T/Ha),G4 (9.591 T/Ha),G6 (9.521 T/Ha),G5 (9.318 T/Ha),G83 $(9.284 \mathrm{~T} / \mathrm{Ha}), \mathrm{G} 16(9.282 \mathrm{~T} / \mathrm{Ha})$ were the top mean yielders across the location (Table 4).

\section{BiPlot}

The AMMI biplot with the genotype and environment main effects for grain yield on the $\mathrm{x}$-axis and the IPCA1 scores on the $\mathrm{y}$-axis is presented in Fig. 2. There are two basic AMMI biplots, the AMMI1 biplot where the main effects (genotype mean and environment mean) and IPCA1 scores for both genotypes and environments are plotted against each other and the AMMI 2 biplot where scores for IPCA1 and IPCA2 are plotted.

Genotypes close to the horizontal line have small interactions and are more stable than those farther from it. The biplot (Figure: 2) revealed large variability among the six test environments and variability among the 171 genotypes tested. The genotypes which are on or close to the horizontal line indicate the IPCA scores for these genotypes are nearer to zero and therefore had small interaction with the environments.G16 was right on the horizontal line with high mean value indicating that G16 is consistent high yielder across the environments tested. G169, G82, G68 G122 \& G151 were average to high yielders and were on the horizontal line indicating that they are average to high yielders with stability across environments. Genotypes G4, G74, G72, G6, G5 and G107 were high yielders with high interaction with environment. The genotypes G-99, G-85, G-
60 and G-103 are poor yielders across environments and are not suitable across growing environments. Genotypes G73, G159, G97 have highest positive IPCV values and G91, G32, G75 and G132 have highest negative IPCV values indicating that these are highly unstable genotypes. Mary Ann et al., 2019 in their study on high zinc breeding material of IRRI indicated that the AMMI and GGE analyses showed significant genotype, environment, and G X E effects for $\mathrm{Zn}$ and YLD across seasons. Many earlier studies have also reported significant genotypic and G XE effects for yield, yield components, and grain micronutrients in rice (Chandel et al. 2010; Rerkasem et al. 2015; Nasrullah 2011; Ajmera et al. 2017).

In AMMI 2 biplot (Figure: 3) the environmental scores are joined to the origin by side lines. Environments with short vectors do not exert strong interactive forces. Those with longer vectors exerts strong interaction. In this study Barabanki (E5) had shorter vector and do not exert strong interactions with genotypes whereas environment Prayagraj (E6) has the longest vector indicating strong GxE interaction at this location. Environments like, Patna (E1), Purnia (E2), Lucknow(E3) and Gosaiganj (E4) had longer vectors and had good interaction with genotypes. The genotypes occurring close together on the plot will tend to have similar yields in all environments, while genotypes far apart may either differ in mean yield or show a different pattern of response over the environments. Hence, the genotypes near the origin are not sensitive to environmental interaction and those distant from the origins are sensitive and have large interaction.

The quadrants proposed by Olivoto, Lúcio, Da silva, Marchioro, et al. (2019) in the following biplot (Figure 3.) represent four classifications regarding the joint 
interpretation of mean performance and stability. The genotypes or environments included in quadrant I can be considered unstable genotypes or environments with high discrimination ability, and with productivity below the grand mean. Genotypes like G138, G97, G48, G84, G94, G86, G43, G31 and checks like G9 (MTU-1010) are unstable genotypes. Environments like Purnia (E2) and Prayagraj (E6) have high discrimination ability. In quadrant II are included unstable genotypes, although with yield higher than the grand mean. The environments included in this quadrant deserve special attention since, in addition to providing high magnitudes of the response variable, they present a good discrimination ability. Environments line Patna (E1), Lucknow (E3) and Barabanki (E5) represent such environments in the study. Genotypes like G72, G107, G46, G157, G58, G46, G57 and check hybrid like Arize6444 Gold registered high yield above mean but unstable. Gosiaganj location was right on the vertical line and can be effectively used to select genotypes which represent the overall trend across six locations. Genotypes within quadrant III have low productivity but can be considered stable due to the lower values of WAASB. The lower this value, the more stable the genotype can be considered. The environments included in this quadrant can be considered as poorly productive and with low discrimination ability. Genotypes like, G81, G100, G19, G125, G106, G14, G121, G108, G14, G64, G67 etc are considered stable genotypes with average to poor yields.

Table.1 Mean squares of analysis of variance (ANOVA) for grain yield across 6 locations

\begin{tabular}{|l|l|l|c|c|c|c|c|}
\hline Source & of & DF & \multicolumn{6}{|c|}{ Mean Sum of squares for grain Yield } \\
Variation & & $\mathbf{E 1}$ & $\mathbf{E 2}$ & $\mathbf{E 3}$ & $\mathbf{E 4}$ & $\mathbf{E 5}$ & E6 \\
\hline Genotype & $\mathbf{1 7 0}$ & $3.752^{* * *}$ & $4.455^{* * *}$ & $2.824^{* * *}$ & $2.3133^{* * *}$ & $3.225^{* * *}$ & $3.519^{* * *}$ \\
\hline Rep & $\mathbf{1}$ & 0 & 0.001 & 0.0057 & 0.0014 & 0.007 & 0.001 \\
\hline Error & $\mathbf{1 7 0}$ & 0.012 & 0.013 & 0.0133 & 0.0125 & 0.013 & 0.014 \\
\hline
\end{tabular}

Table.2 Mean squares of analysis of variance (ANOVA) for grain yield across 6 locations

\begin{tabular}{|l|c|c|}
\hline Source of Variation & DF & Mean squares for Grain Yield \\
\hline Hybrid & $\mathbf{1 7 0}$ & $16.74^{* * *}$ \\
\hline Rep & $\mathbf{1}$ & 0.01 \\
\hline Location & $\mathbf{5}$ & $97.3^{* * *}$ \\
\hline GE*Location & $\mathbf{8 5 0}$ & $0.67^{* * *}$ \\
\hline Residuals & $\mathbf{1 0 2 5}$ & 0.01 \\
\hline
\end{tabular}


Table.3 AMMI analysis for grain yield (T/Ha) of rice Hybrids across 6 locations

\begin{tabular}{|c|c|c|c|c|c|c|c|}
\hline Source of Variation & Df & SS & $\begin{array}{l}\text { Explained } \\
\text { TSS (\%) }\end{array}$ & MS & $\mathbf{F}$ & p -value & $\begin{array}{l}\text { Explain } \\
\text { ed }(\%)\end{array}$ \\
\hline Environment (E) & 5 & 486.52 & 10.85 & 97.305 & 34884.5 & $2.6712 \mathrm{E}-13 * * *$ & \\
\hline $\begin{array}{l}\text { Replicate/Environ } \\
\text { ment }\end{array}$ & 6 & 0.02 & 0.00 & 0.003 & 0.21 & 0.9726 & \\
\hline Genotype (G) & 170 & 2845.4 & 63.45 & 16.737 & 1281.0 & $<0.001 * * *$ & \\
\hline Interaction (GE) & 850 & 569.6 & 12.70 & 0.670 & 51.29 & $<0.001 * * *$ & \\
\hline IPCA1 & 174 & 157.9 & 3.52 & 0.908 & 69.48 & $<0.0001 * * *$ & 27.7 \\
\hline IPCA2 & 172 & 133.5 & 2.98 & 0.777 & 59.41 & $<0.0001 * * *$ & 23.4 \\
\hline IPCA3 & 170 & 112.8 & 2.51 & 0.663 & 50.77 & $<0.0001 * * *$ & 19.8 \\
\hline IPCA4 & 168 & 91.3 & 2.04 & 0.544 & 41.59 & $<0.0001 * * *$ & 16 \\
\hline IPCA5 & 166 & 74.09 & 1.65 & 0.447 & 34.16 & $<0.0001 * * *$ & 13 \\
\hline Residual & 1020 & 13.33 & 0.30 & 0.0131 & NA & NA & \\
\hline Total & 2901 & 4484.4 & 100.00 & 1.546 & NA & NA & $\langle\mathrm{NA}\rangle$ \\
\hline
\end{tabular}

Table.4 High Yielding rice hybrids and their IPCA score for grain yield (T/Ha)

\begin{tabular}{|l|l|c|c|c|c|c|c|}
\hline $\begin{array}{l}\text { Genotype } \\
\text { Code }\end{array}$ & Genotype & $\begin{array}{c}\text { Grain Yield } \\
(\mathbf{T} / \mathbf{h a})\end{array}$ & IPCA1 & IPCA2 & IPCA3 & IPCA4 & IPCA5 \\
\hline G4 & 27 37 & 9.591 & 0.09102 & -0.258 & -0.074 & 0.2643 & -0.3369 \\
\hline G5 & 28 P67 & 9.318 & -0.0640 & 0.178 & -0.050 & 0.2936 & 0.1082 \\
\hline G6 & BSBArize6444 Gold & 9.521 & 0.1994 & 0.311 & -0.390 & 0.0268 & 0.4713 \\
\hline G16 & PLIR75589TGMS/IR07A250 & 9.282 & 0.00790 & 0.206 & 0.4502 & -0.146 & 0.1168 \\
\hline G58 & PLIR75589TGMS/PL1823315 & 9.672 & -0.1355 & -0.304 & -0.128 & 0.2659 & 0.2398 \\
\hline G72 & PLIR75589TGMS/PLADT44 & 9.954 & 0.4226 & 0.228 & 0.0804 & -0.1724 & -0.5531 \\
\hline G74 & PLIR75589TGMS/PLASD20 & 9.798 & 0.2819 & 0.1112 & 0.1104 & -0.2761 & 0.01249 \\
\hline G83 & PLIR75589TGMS/PLChampa & 9.284 & -0.0651 & 0.1951 & 0.1835 & -0.2428 & -0.1721 \\
\hline G107 & PLIR75589TGMS/PLIR547452231983 & 9.621 & 0.2017 & 0.5319 & 0.2832 & 0.1302 & 0.1709 \\
\hline
\end{tabular}


Table.5 Performance of genotypes and their IPCA1 score for yield (mt/ha)

\begin{tabular}{|c|c|c|c|c|c|c|c|}
\hline Code & Hybrid & $\begin{array}{l}\text { Yield } \\
\text { (T/ha) }\end{array}$ & IPCA1 & Code & Hybrid & $\begin{array}{l}\text { Yield } \\
\text { (T/ha) }\end{array}$ & IPCA1 \\
\hline G1 & 25P35 & 7.29 & -0.216 & G47 & Hyb-73 & 9.08 & 0.246 \\
\hline G2 & 27P22 & 8.72 & 0.309 & G48 & Hyb-75 & 7.46 & -0.160 \\
\hline G3 & 27P31 & 8.88 & 0.305 & G49 & Hyb-77 & 8.07 & -0.249 \\
\hline G4 & 27P37 & 9.59 & 0.091 & G50 & Hyb-79 & 7.89 & -0.107 \\
\hline G5 & 28P67 & 9.32 & -0.064 & G51 & Hyb-81 & 7.77 & 0.275 \\
\hline G6 & $\begin{array}{l}\text { Arize6444 } \\
\text { Gold }\end{array}$ & 9.52 & 0.199 & G52 & Hyb-83 & 6.10 & -0.313 \\
\hline G7 & PHB71 & 8.30 & -0.100 & G53 & Hyb-86 & 8.15 & -0.035 \\
\hline G8 & US312 & 7.88 & 0.233 & G54 & Hyb-87 & 7.87 & 0.187 \\
\hline G9 & MTU1010 & 4.96 & -0.361 & G55 & Hyb-89 & 7.21 & -0.108 \\
\hline G10 & NDR359 & 6.42 & -0.187 & G56 & Hyb-91 & 7.36 & 0.286 \\
\hline G11 & Hyb-02 & 7.64 & 0.234 & G57 & Hyb-93 & 8.07 & 0.075 \\
\hline G12 & Hyb-04 & 7.54 & 0.316 & G58 & Hyb-95 & 9.67 & -0.136 \\
\hline G13 & Hyb-06 & 8.44 & -0.078 & G59 & Hyb-97 & 7.70 & 0.113 \\
\hline G14 & Hyb-08 & 7.30 & -0.161 & G60 & Hyb-99 & 3.82 & 0.120 \\
\hline G15 & Hyb-10 & 8.19 & 0.106 & G61 & Hyb-101 & 7.28 & -0.010 \\
\hline G16 & Hyb-12 & 9.28 & 0.008 & G62 & Hyb-103 & 7.11 & -0.037 \\
\hline G17 & Hyb-14 & 7.53 & -0.099 & G63 & Hyb-105 & 8.89 & 0.092 \\
\hline G18 & Hyb-16 & 8.26 & 0.024 & G64 & Hyb-107 & 7.42 & 0.049 \\
\hline G19 & Hyb-18 & 7.14 & -0.034 & G65 & Hyb-109 & 8.15 & 0.072 \\
\hline G20 & Hyb-20 & 8.77 & -0.198 & G66 & Hyb-111 & 7.81 & 0.126 \\
\hline G21 & Hyb-22 & 8.97 & -0.258 & G67 & Hyb-113 & 7.35 & 0.005 \\
\hline G22 & Hyb-24 & 7.24 & 0.076 & G68 & Hyb-115 & 8.40 & 0.006 \\
\hline G23 & Hyb-26 & 8.59 & 0.195 & G69 & Hyb-117 & 7.85 & 0.367 \\
\hline G24 & Hyb-28 & 7.28 & -0.069 & G70 & Hyb-120 & 7.77 & -0.045 \\
\hline G25 & Hyb-30 & 7.77 & -0.311 & G71 & Hyb-121 & 7.84 & -0.007 \\
\hline G26 & Hyb-32 & 5.66 & -0.495 & G72 & Hyb-123 & 9.95 & 0.423 \\
\hline G27 & Hyb-34 & 8.12 & 0.242 & G73 & Hyb-125 & 8.44 & 0.189 \\
\hline G28 & Hyb-36 & 7.96 & 0.281 & G74 & Hyb-127 & 9.80 & 0.282 \\
\hline G29 & Hyb-38 & 7.63 & 0.264 & G75 & Hyb-129 & 6.38 & -0.579 \\
\hline G30 & Hyb-40 & 7.63 & 0.146 & G76 & Hyb-131 & 6.61 & 0.043 \\
\hline G31 & Hyb-42 & 6.12 & -0.538 & G77 & Hyb-133 & 6.70 & -0.013 \\
\hline G32 & Hyb-44 & 9.19 & -0.367 & G78 & Hyb-136 & 7.86 & 0.054 \\
\hline G33 & Hyb-46 & 7.05 & -0.175 & G79 & Hyb-137 & 7.73 & -0.101 \\
\hline G34 & Hyb-48 & 8.79 & 0.428 & G80 & Hyb-139 & 6.96 & -0.030 \\
\hline G35 & Hyb-50 & 7.66 & 0.036 & G81 & Hyb-141 & 7.54 & -0.130 \\
\hline G36 & Hyb-52 & 7.87 & 0.296 & G82 & Hyb-144 & 8.56 & 0.005 \\
\hline G37 & Hyb-54 & 7.86 & -0.059 & G83 & Hyb-145 & 9.28 & -0.065 \\
\hline G38 & Hyb-55 & 7.83 & 0.015 & G84 & Hyb-147 & 6.93 & -0.291 \\
\hline
\end{tabular}




\begin{tabular}{|c|c|c|c|c|c|c|c|}
\hline G39 & Hyb-58 & 7.96 & 0.086 & G85 & Hyb-149 & 4.48 & 0.186 \\
\hline G40 & Hyb-60 & 5.48 & -0.346 & G86 & Hyb-151 & 5.08 & -0.475 \\
\hline G41 & Hyb-62 & 6.53 & -0.049 & G87 & Hyb-153 & 7.50 & -0.084 \\
\hline G42 & Hyb-63 & 7.04 & 0.133 & G88 & Hyb-155 & 7.26 & 0.215 \\
\hline G43 & Hyb-65 & 7.53 & 0.277 & G89 & Hyb-157 & 6.94 & 0.031 \\
\hline G44 & Hyb-67 & 9.26 & -0.100 & G90 & Hyb-159 & 7.52 & -0.055 \\
\hline G45 & Hyb-69 & 8.18 & 0.208 & G91 & Hyb-161 & 5.81 & -0.673 \\
\hline G46 & Hyb-71 & 9.15 & 0.258 & G92 & Hyb-163 & 8.27 & -0.134 \\
\hline Code & Hybrid & $\begin{array}{l}\text { Yield } \\
\text { (T/ha) }\end{array}$ & IPCA1 & Code & Hybrid & $\begin{array}{l}\text { Yield } \\
\text { (T/ha) }\end{array}$ & IPCA1 \\
\hline G93 & Hyb-165 & 7.42 & -0.046 & G137 & Hyb-253 & 7.83 & 0.134 \\
\hline G94 & Hyb-167 & 6.24 & -0.376 & G138 & Hyb-255 & 5.49 & -0.623 \\
\hline G95 & Hyb-169 & 5.84 & 0.028 & G139 & Hyb-257 & 5.46 & -0.285 \\
\hline G96 & Hyb-171 & 7.61 & 0.040 & G140 & Hyb-259 & 8.52 & 0.199 \\
\hline G97 & Hyb-173 & 6.56 & 0.644 & G141 & Hyb-261 & 8.15 & -0.027 \\
\hline G98 & Hyb-175 & 7.97 & 0.001 & G142 & Hyb-263 & 8.05 & 0.217 \\
\hline G99 & Hyb-177 & 4.09 & 0.025 & G143 & Hyb-265 & 8.29 & 0.200 \\
\hline G100 & Hyb-179 & 7.61 & 0.171 & G144 & Hyb-267 & 7.95 & 0.215 \\
\hline G101 & Hyb-181 & 5.51 & -0.325 & G145 & Hyb-269 & 7.98 & 0.306 \\
\hline G102 & Hyb-183 & 6.87 & -0.162 & G146 & Hyb-271 & 7.07 & -0.331 \\
\hline G103 & Hyb-185 & 3.21 & -0.110 & G147 & Hyb-273 & 5.28 & -0.412 \\
\hline G104 & Hyb-187 & 7.58 & 0.127 & G148 & Hyb-275 & 7.93 & 0.124 \\
\hline G105 & Hyb-189 & 6.41 & -0.367 & G149 & Hyb-277 & 6.71 & -0.278 \\
\hline G106 & Hyb-191 & 7.24 & 0.019 & G150 & Hyb-279 & 8.16 & -0.184 \\
\hline G107 & Hyb-193 & 9.62 & 0.202 & G151 & Hyb-282 & 8.47 & -0.004 \\
\hline G108 & Нyb-195 & 7.28 & -0.088 & G152 & Hyb-283 & 7.20 & -0.291 \\
\hline G109 & Hyb-197 & 8.20 & 0.142 & G153 & Hyb-285 & 6.41 & 0.086 \\
\hline G110 & Hyb-199 & 5.94 & -0.111 & G154 & Hyb-287 & 8.23 & 0.116 \\
\hline G111 & Hyb-201 & 8.48 & 0.229 & G155 & Hyb-289 & 7.70 & 0.168 \\
\hline G112 & Hyb-203 & 7.78 & 0.199 & G156 & Hyb-292 & 6.71 & -0.363 \\
\hline G113 & Hyb-205 & 7.80 & 0.329 & G157 & Hyb-293 & 9.27 & 0.137 \\
\hline G114 & Hyb-207 & 7.89 & -0.087 & G158 & Hyb-295 & 7.44 & -0.169 \\
\hline G115 & Hyb-209 & 8.05 & -0.072 & G159 & Hyb-297 & 8.32 & 0.138 \\
\hline G116 & Hyb-211 & 6.73 & -0.069 & G160 & Hyb-299 & 8.54 & -0.096 \\
\hline G117 & Hyb-213 & 6.75 & -0.110 & G161 & Hyb-301 & 8.00 & 0.304 \\
\hline G118 & Hyb-215 & 6.79 & -0.320 & G162 & Hyb-303 & 8.79 & 0.110 \\
\hline G119 & Hyb-217 & 7.66 & -0.318 & G163 & Hyb-306 & 6.97 & -0.094 \\
\hline G120 & Hyb-219 & 8.84 & 0.186 & G164 & Hyb-307 & 8.79 & -0.150 \\
\hline G121 & Hyb-221 & 7.35 & -0.273 & G165 & Hyb-309 & 6.98 & 0.285 \\
\hline G122 & Hyb-223 & 8.02 & -0.023 & G166 & Hyb-311 & 8.03 & 0.306 \\
\hline G123 & Hyb-225 & 6.83 & 0.206 & G167 & Hyb-313 & 9.24 & 0.448 \\
\hline G124 & Hyb-227 & 7.46 & 0.038 & G168 & Hyb-315 & 7.20 & -0.028 \\
\hline G125 & Hyb-229 & 7.29 & -0.142 & G169 & Hyb-317 & 8.39 & 0.042 \\
\hline
\end{tabular}




\begin{tabular}{|l|l|l|l|l|l|l|l|}
\hline G126 & Hyb-231 & 6.04 & -0.055 & G170 & Hyb-319 & 3.81 & 0.361 \\
\hline G127 & Hyb-233 & 7.90 & 0.325 & G171 & Hyb-321 & 6.40 & -0.142 \\
\hline G128 & Hyb-235 & 8.97 & 0.084 & & & & \\
\hline G129 & Hyb-237 & 8.43 & 0.296 & Environments & & \\
\hline G130 & Hyb-239 & 8.08 & -0.129 & Patna (E1) & 8.01 & -0.39 \\
\hline G131 & Hyb-241 & 8.44 & -0.213 & Purnia (E2) & 6.975 & 1.645 \\
\hline G132 & Hyb-243 & 7.50 & 0.086 & Lucknow (E3) & 8.04 & -1.165 \\
\hline G133 & Hyb-245 & 7.36 & -0.051 & Gosaiganj (E4) & 7.512 & -1.551 \\
\hline G134 & Hyb-247 & 5.60 & -0.313 & Barabanki (E5) & 7.913 & -0.0444 \\
\hline G135 & Hyb-249 & 7.70 & -0.165 & Prayagraj (E6) & 6.837 & 1.505 \\
\hline G136 & Hyb-251 & 6.97 & 0.019 & & & \\
\hline
\end{tabular}

Figure.1 Locations details where yield trials were planted

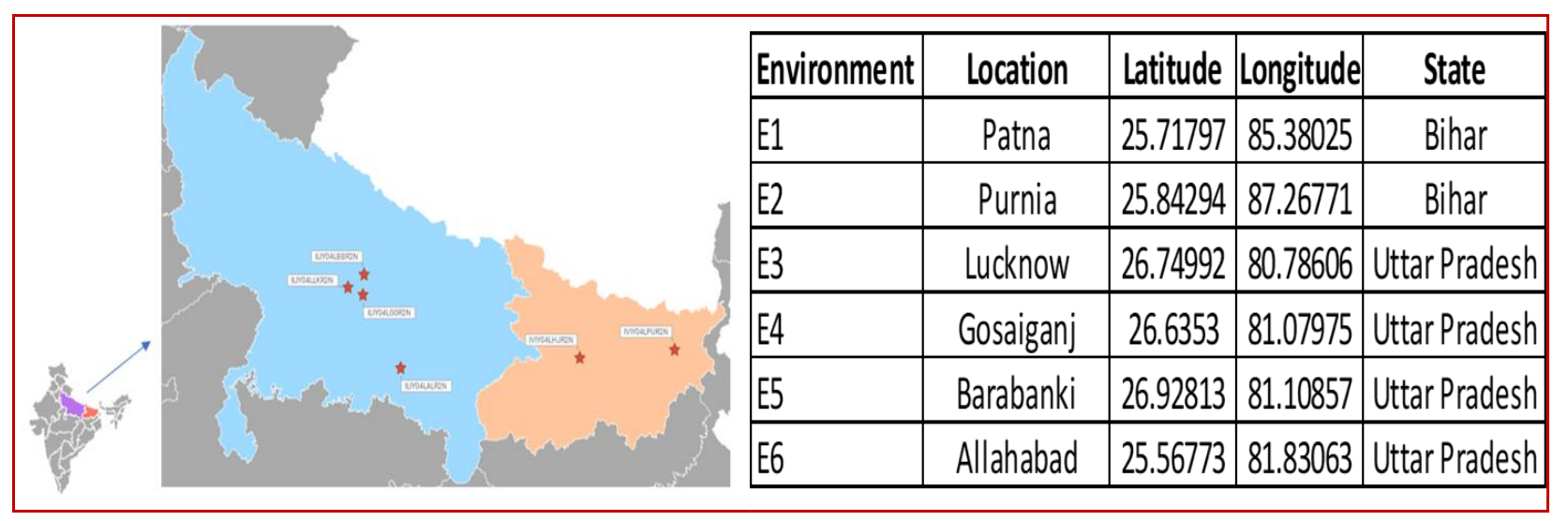

Figure.2 AMMI BiPlot 1

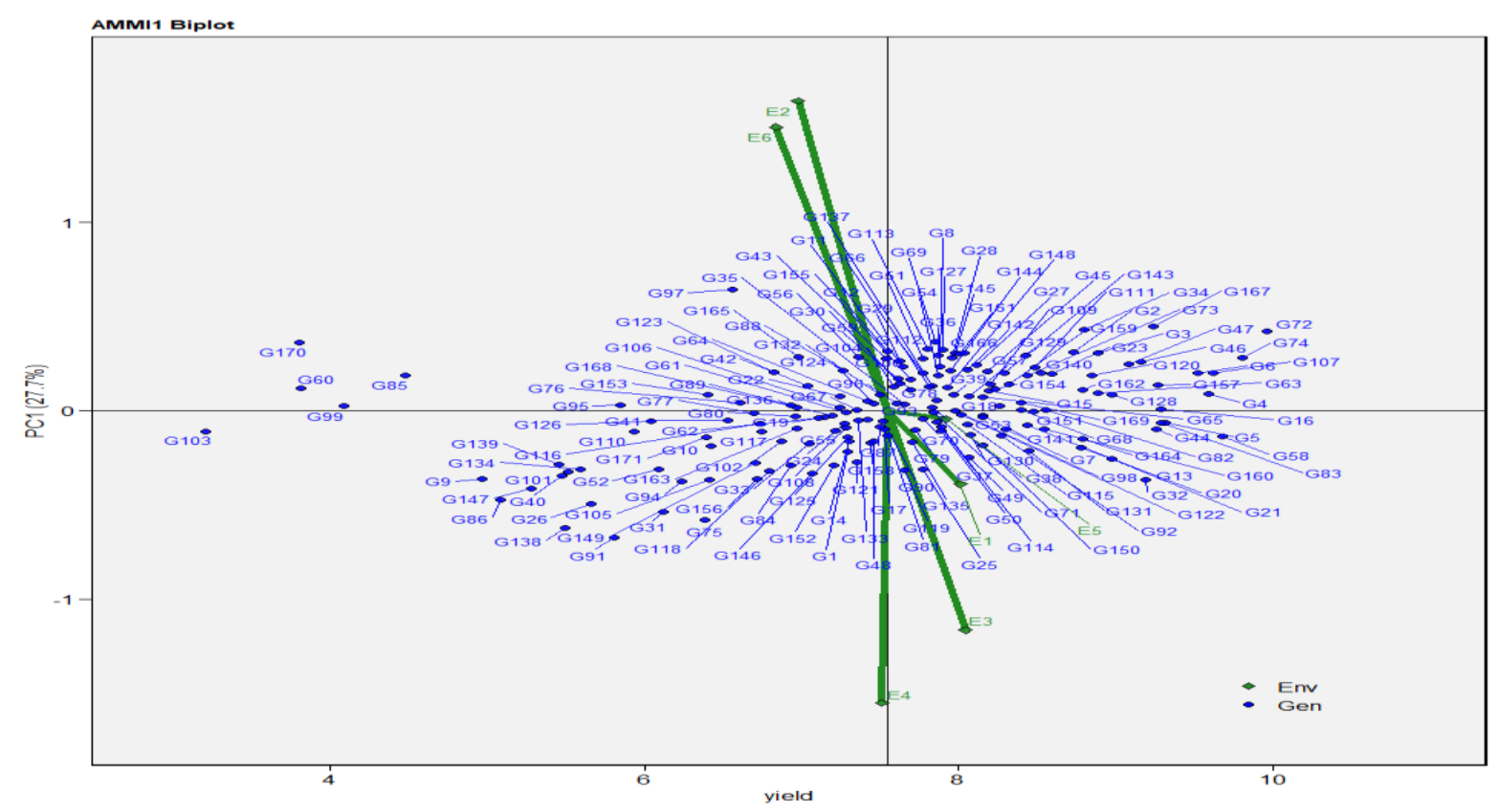


Figure.3 AMMI BiPlot 2

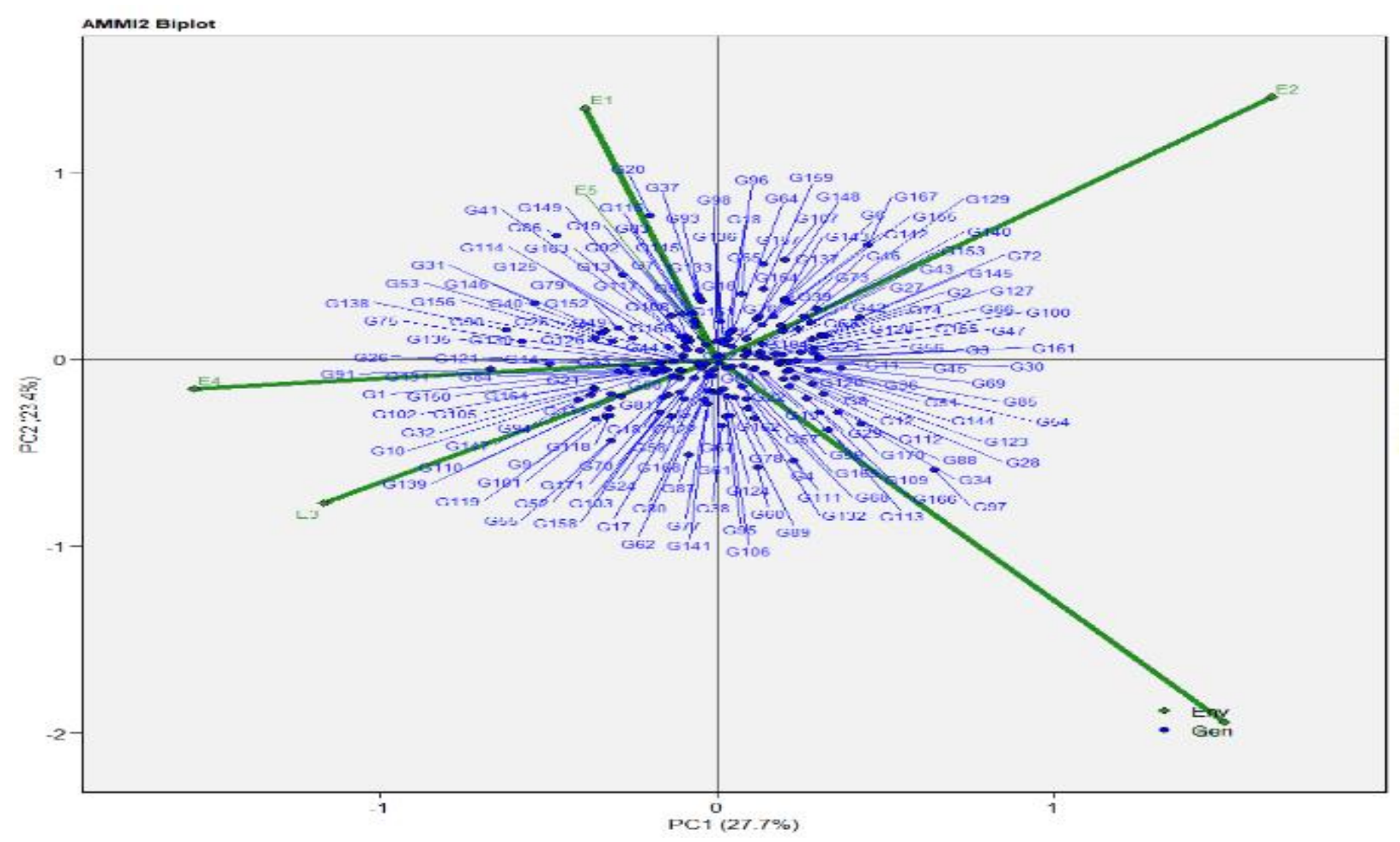

Figure.4 Y x WAAS BiPlot

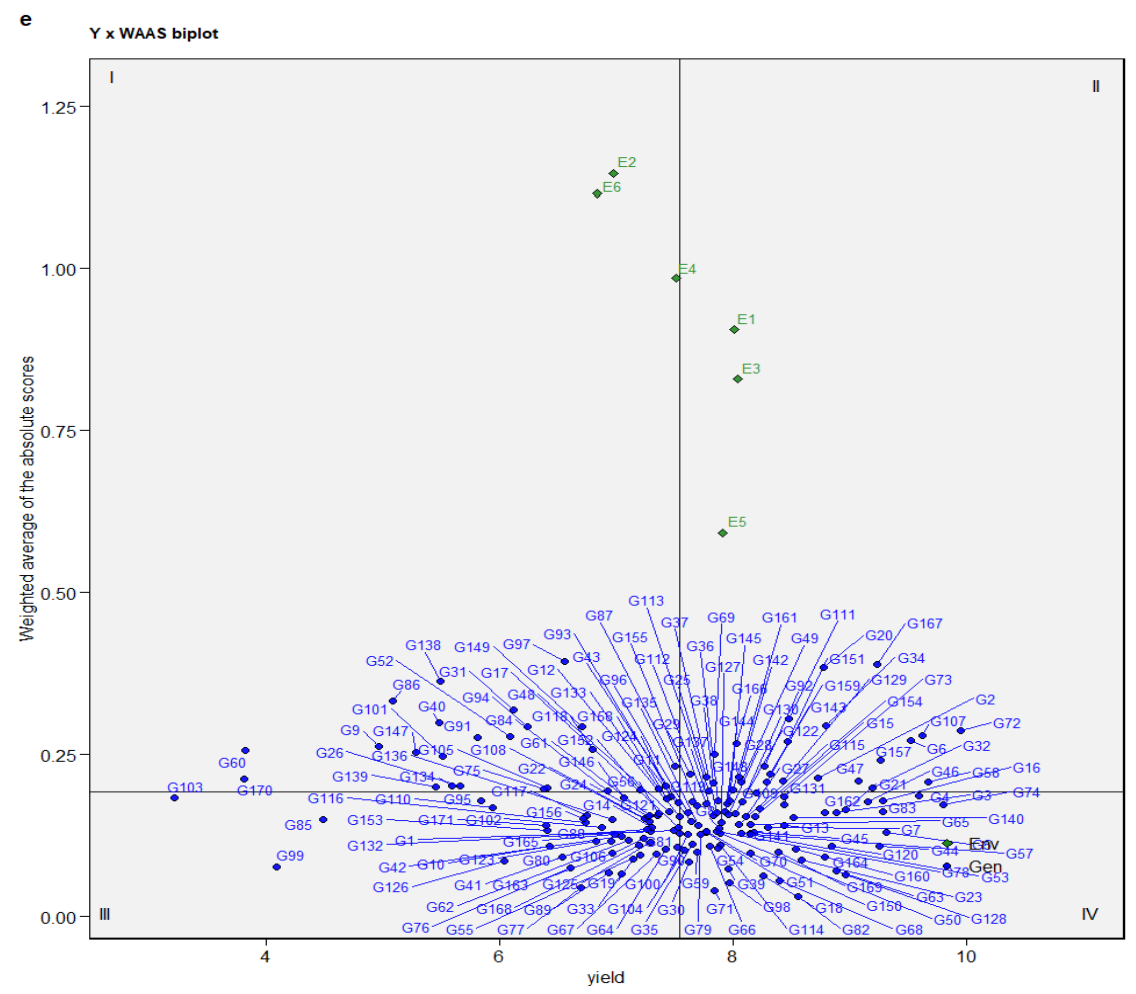


The genotypes within the quadrant IV are highly productive and broadly adapted due to the high magnitude of the response variable and high stability performance (lower values of WAASB). Genotypes like, G4, G74.G3, G83, G16, G7, G78, G44, G120 \& G46 are high yielding and fairly stable hybrids across tested environments.

This study indicated the presence of large GXE interaction across the tested environments. The genotype G16 (PLIR75589TGMS/IR07A250) is a consistent high yielder across the environments tested and is recommended for cultivation in the sampled environments. G169, G82, G68 G122 \& G151 arethe second set of high yielding stable hybrids cross environments. Genotypes G4, G74, G72, G6, G5 and G107 were high yielders with high interaction with environment and therefore can be recommended to specific locations were they are performing well with lease environmental interaction.

\section{References}

Ajmera. S., Kumar, S, S. \& Ravindrababu, V. (2017).'Genotype $\quad 9$ environment interactions and stability analysis for grain iron and zinc concentrations in rice (Oryza sativa L.) genotypes'. Int J Curr Microbiol Appl Sci 6:1902-1913

Anandan A. (2011). 'AMMI analysis to comprehend genotype-by environment $(\mathrm{G} \times \mathrm{E})$ interactions in rainfed grown mungbean'. AJCS 5(13):17671775.

Bharat Taindu Jain., Ashok Kumar Sarial. \& Prashant Kaushik, (2018). 'Stability analysis utilizing ammi model and regression analysis for grain yield of basmati rice (Oryza sativa L.) Genotypes'. Journal of Experimental Biology and Agricultural Sciences, June - 2018; Volume - 6(3) page 522 - 530

Chandel, G., Banerjee, S., See S., Meena, R.,
Sharma, D.J. \& Verulkar, S.B. (2010). 'Effect of different nitrogen fertilizer levels and native soil properties on rice grain $\mathrm{Fe}, \mathrm{Zn}$ and protein contents'. Rice Sci 17:213-227 Crossa, J.,

Eberhart S, A. \& Russel WA (1966. Stability parameters for comparing varieties. Crop Sciences 6: 36-40.

Finlay K, W. \& Wilkinson GN (1963). 'The analysis of adaptation in a plant breeding programmed'. Australian Journal Agriculture Research 14: 42754.

Gauch, H.G. (1988). 'Model selection and validation for yield trials with interaction'. Biometrics 44:705-715

Kempton R.A. (1984). 'The use of biplots in interpreting variety by environment interaction'. J Agric Sci. 103:123-135.

Khush, G.S. (2013). 'Strategies for increasing the yield potential of cereals: case of rice as an example'. Plant Breed. 132:433-436

Linnemann, A., Westphal, E. and Wessel, M. (1995). 'Photoperiod regulation of development and growth in bambara groundnut (Vigna subterranea)'. Field Crops Res. 40 : 39-47.

Lin CS., Binns MR. \& Lefkovitch, LP. (1986). 'Stability analysis, where do we stand'. Crop Sci. 26:894.

Lopez, M. T., Virmani, S. S. (2000). 'Development of TGMS lines for developing two-line rice hybrids for the tropics'. Euphytica, 114(2): 211-215.

Mahalingam A, N., Manivannan, S., Lakshmi Narayanan. \& S. Sowmya Sree. (2018). 'AMMI analysis of phenotypic stability in greengram (Vigna radiata (L.) Wilczek) genotypes over seasons'. Crop Research. 53 (3 \& 4): 131 - 134.

Mary Ann Inabangan-Asilo., B. P. Mallikarjuna Swamy., Amery F. Amparado., Gwen Iris L., DescalsotaEmpleo., Emily C. Arocena.\& Russell Reinke., (2019). 'Stability and G 3 E 
analysis of zinc-biofortified rice genotypes evaluated in diverse environments. Euphytica (2019) 215:61

Mohammadi R., Abdulahi A., Haghparast R. \& Armion M (2007). 'Interpreting genotype-environment interactions for durum wheat grain yields using nonparametric methods'. Euphytica. 157:239-251

Ponnuswamy, R., Rathore, A., Vemula, R.R., Das, A. K. Singh., Balakrishnan, D., Arremsetty, H.S., Vemuri, R.B. \& Ram, $T$ (2017). 'Analysis of Multi-location Data of Hybrid Rice Trials Reveals Complex Genotype by Environment Interaction'. Cereal Research Communications 46(1), pp. 146-157 (2018)

Rerkasem, B., Jumrus, S., Yimyam, N. \& Prom-u-thai C (2015).'Variation of grain nutritional quality among Thai purple rice genotypes grown at two different altitudes'. Sci Asia 41:377385

Sabaghnia N., Sabaghpour SH. \& Dehghani H (2008). 'The use of an AMMI model and its parameters to analyse yield stability in multi environment trials'. J Agric Sci. 146(5):571-581.

Shams Shaila Islam., Jakarat Anothai., Charassri Nualsri. \& Watcharin Soonsuwon. (2020). 'Analysis of genotype-environment interaction and yield stability of Thai upland rice (Oryza sativa L.) genotypes using
AMMI model'. AJCS 14(02):362-370 (2020)

Nasrullah, Suwarto. (2011). 'Genotype 9 environment interaction for iron concentration of rice in Central Java of Indonesia'. Rice Sci 18:75-78

Tiago Olivoto., Alessandro D.C., Lúcio,José A.G. da Silva, Volmir S. Marchioro, Velci Q. de Souza, \& Evandro Jost. (2019). Mean Performance and stability in Multi-Environment Trials I: Combining Features of AMMI and BLUP Techniques. Agronomy Journal.

Yan W. \& Hunt L. A. (2001). 'Interpretation of genotype environment interaction for winter wheat yield in Ontario'. Crop Sci. 41:19-25

Yates F, \& Cochran W. G (1938). 'The analysis of groups of experiments. Journal of Agricultural Science' 28: $556-580$

Yuan, L. P. (1997). 'Exploiting crop heterosis by two-line system hybrids: Current status and future prospects'. In: Proceedings of International Symposium on Two-Line System of Heterosis Breeding in Crops. Sep. 6-8, 1997. Changsha, China: China National Hybrid Rice Research and Development Centre: 215-220.

Zobel, R. W., Wright, M. J. \& Gauch, H. G. (1988). 'Statistical analysis of a yield trial'. Agron. J. $80: 388-93$.

\section{How to cite this article:}

Somanagoudra, Chandrashekhar and Manonmani, S. 2020. Stability Analysis of Two-line Rice Hybrids (Oryza sativa) in Diverse Environments Utilizing AMMI Model. Int.J.Curr.Microbiol.App.Sci. 9(06): 1033-1044. doi: https://doi.org/10.20546/ijcmas.2020.906.129 